dystrophic nature, with no severe dilatation of the aortic root.

The third question relates to the risk of complete atrioventricular block after CoreValve System implantation. Several predictors, including pre-existing right bundle branch block, have been determined and should lead to careful and prolonged predischarge monitoring, all the more because these conduction disturbances can be delayed, as was the case in the present report. ${ }^{5}$

In the future, the treatment of AR by means of TAVI will probably remain restricted to very particular and individual cases but might be life-saving or contribute to an improvement in the functional status of patients with no other therapeutic options.

\section{References}

1. Vahanian A, Alfieri O, Al-Attar N, Antunes MJ, Bax J, Cormier B, et al. Transcatheter valve implantation for patients with aortic stenosis: a position statement from the European Association of Cardio-Thoracic Surgery (EACTS) and the European Society of Cardiology (ESC), in collaboration with the European Association of Percutaneous Cardiovascular Interventions (EAPCI). Eur Heart J. 2008;29:1463-70.

2. Walther T, Falk V, Dewey T, Kempfert J, Emrich F, Pfannmuller B, et al. Valve-invalve concept for transcatheter minimally invasive repeat xenograft implantation. J Am Coll Cardiol. 2007;50:56-60.

3. Wenaweser P, Buellesfeld J, Gerckens U, Grube E. Percutaneous aortic valve replacement for severe aortic regurgitation in degenerated bioprosthesis: the first valve in valve procedure using the CoreValve Revalving System. Catheter Cardiovasc Interv. 2007;70:760-4.

4. Attias D, Himbert D, Hvass U, Vahanian A. "Valve-in-valve" implantation in a patient with stentless bioprosthesis and severe intraprosthetic aortic regurgitation. J Thorac Cardiovasc Surg. 2009;138:102-2.

5. Piazza N, Nuis RJ, Tzikas A, Schultz C, Onuma Y, Otten A, et al. Persistent conduction abnormalities and requirements for pacemaking 6 months after transcatheter aortic valve implantation. Circulation. 2009;120(suppl):S949-50.

\title{
Less invasive left ventricular assist device placement for difficult resternotomy
}

\author{
Hiroo Takayama, MD, ${ }^{\text {a }}$ Yoshifumi Naka, MD, PhD, ${ }^{\mathrm{a}}$ Ulrich P. Jorde, MD, ${ }^{\mathrm{b}}$ and Allan S. Stewart, MD, ${ }^{\mathrm{a}}$
} New York, NY

Left ventricular assist devices (LVADs) are playing an increasingly important role in the management of end-stage heart failure, especially with the advances in technology in implantable LVADs. Placement of an implantable LVAD generally requires a median sternotomy, and this approach might not be suitable for unstable patients with difficult resternotomy. Even in such a situation, however, current state-of-the-art technology can provide mechanical circulatory support either with extracorporeal membrane oxygenation (ECMO) or, more recently, with percutaneous LVADs. ${ }^{1,2}$ The shortcoming of the latter modalities is that they are not designed for prolonged periods of support. Here we describe a unique configuration of the CentriMag LVAD (Thoratec Corp, Pleasanton, Calif) that allowed rapid off-pump placement of the device without performing a sternotomy.

\footnotetext{
From the Divisions of Cardiothoracic Surgery ${ }^{\mathrm{a}}$ and Cardiology, ${ }^{\mathrm{b}}$ Columbia University Medical Center, New York, NY.

Disclosures: None.

Received for publication March 8, 2010; revisions received April 14, 2010; accepted for publication April 26, 2010; available ahead of print June 11, 2010.

Address for reprints: Allan S. Stewart, MD, Columbia University Medical Center, Milstein Hospital Building, 7-435, 177 Fort Washington Ave, New York, NY 10032 (E-mail: as2276@columbia.edu).

J Thorac Cardiovasc Surg 2010;140:932-3

$0022-5223 / \$ 36.00$

Copyright (c) 2010 by The American Association for Thoracic Surgery doi:10.1016/j.jtcvs.2010.04.028
}

\section{CLINICAL SUMMARY}

The patient was a 50-year-old man (height, $180 \mathrm{~cm}$; weight, $105 \mathrm{~kg}$ ) with nonischemic dilated cardiomyopathy. He previously had 2 sternotomies; the first was an aortic valve replacement with a mechanical valve for congenital bicuspid aortic valve 8 years ago, and the second was a hemiarch repair of a type A aortic dissection 4 years ago. The patient first had symptoms of congestive heart failure (CHF) about 6 years ago, with recent progression requiring multiple hospitalizations, and was listed for heart transplantation. His condition recently further deteriorated, with acutely decompensated CHF and ventricular arrhythmia requiring admission to the intensive care unit. Although CHF improved with infusion of inotropic agents, ventricular arrhythmia persisted and became more frequent, with multiple firings of his implantable cardioverter defibrillator. Intra-aortic balloon pump therapy was not applicable because of the remaining aortic dissection in the descending aorta. At this point, urgent LVAD support was deemed necessary.

The patient was taken to the operating room. In the supine position general anesthesia was induced with a single-lumen endotracheal tube. The previous right axillary artery cannulation site was opened, and the artery was exposed. A left anterior minithoracotomy through the sixth intercostal space was performed, and the left ventricular apex was exposed by dissecting some loose adhesion inside of the pericardium. 
Heparin $(150 \mathrm{U} / \mathrm{kg})$ was administered intravenously. An 8-mm graft was sewn end to side to the right axillary artery, and a 24F EOPA arterial cannula (Medtronic, Inc, Minneapolis, Minn), brought through a separate skin incision, was inserted and secured to the graft. Next, $2-0$ double purse-string sutures buttressed by bovine pericardial pledgets were placed at the apex, and the apex was punctured with a needle through which a guidewire was inserted into the left ventricle. After serial dilatation with the Vascular Dilator Kit (Estech, Inc, San Ramon, Calif), a 40F Lighthouse malleable cannula (Edwards Lifesciences LLC, Irvine, Calif) was inserted into the left ventricle, and the purse-string sutures were snared. The position of the left ventricular cannula was confirmed with transesophageal echocardiographic analysis. The cannula was secured to the snares and was brought out though a separate skin incision at the left anterior chest (Figure 1). The cannulae were connected to the CentriMag LVAD, and the LVAD was actuated with caution to maintain forward flow through the mechanical aortic valve. A flow of more than $4 \mathrm{~L} / \mathrm{min}$ was achieved easily. No blood transfusion was required. The heparin drip was resumed immediately for the mechanical aortic valve. The patient was extubated on postoperative day 1 and is waiting for heart transplantation in stable condition. No further ventricular arrhythmia was observed.

\section{DISCUSSION}

Recently reported 30-day survival rates after long-term mechanical circulatory support device insertion are approximately $80 \%$ to $90 \%$. ${ }^{3}$ Estimated operative mortality rates from the revised Columbia screening scale, developed with a focus on operative mortality, are approximately $5 \%$ for low-risk patients and approximately $45 \%$ for high-risk patients. ${ }^{4}$ An important lesson learned from the previous experience was that patient selection is the key to the success of LVAD implantation, and in fact, better patient selection has contributed to decreasing operative mortality. ${ }^{5,6}$ In reality, however, cardiac surgeons are frequently faced with a critically ill patient who has a high-risk profile but likely will not survive without ventricular assist device (VAD) support. The outcome with an implantable LVAD in this situation has been shown to be unsatisfactory, and therefore alternate measures are sought in these circumstances. These include ECMO, a percutaneous VAD, and a short-term/ nonimplantable VAD, such as CentriMag or Abiomed BVS/AB 5000. As stated above, ECMO and a percutaneous VAD allow only limited duration of support, and the use of a short-term VAD with the regular insertion technique requires a median sternotomy. None of these devices or techniques would have accommodated our patient with 2 prior sternotomies and ideally requiring full postoperative mobilization/rehabilitation before undergoing heart transplantation. Accordingly, we chose the left ventricular apex as a cannulation site for the inflow cannula and the right

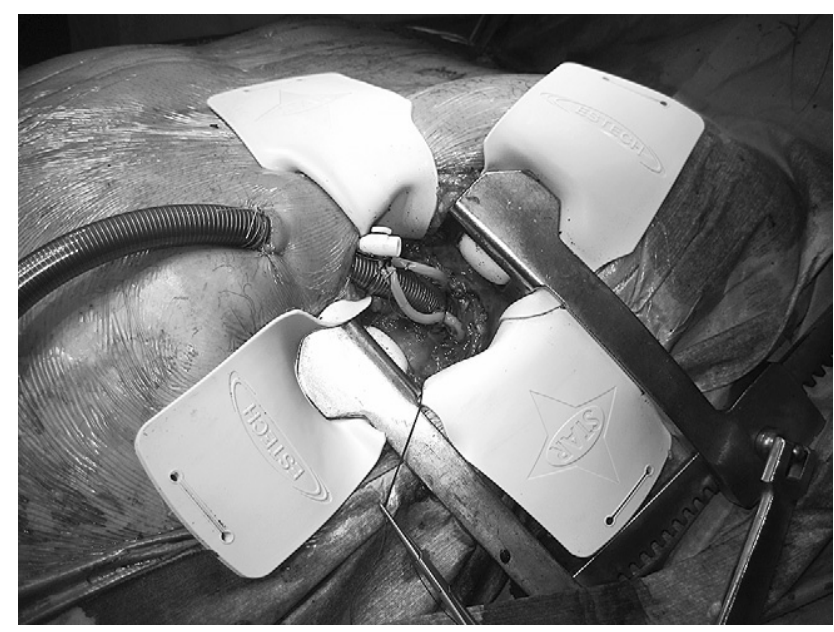

FIGURE 1. An inflow cannula was inserted into the left ventricle through the apex, which was exposed with an anterior left minithoracotomy.

axillary artery as that for the outflow cannula, thus avoiding a third sternotomy. The right axillary artery was chosen over the left because of the existing implantable cardioverter defibrillator. The feasibility of these access sites has been established through experience in the transapical approach for aortic valve replacement and right axillary cannulation for aortic surgery. This configuration allowed a less invasive approach and yet provided excellent flow. For this particular patient, forward flow through his mechanical aortic valve was maintained to prevent thrombus formation by adjusting the LVAD flow. Although the CentriMag is currently approved only for short-term support, in our program we have used the CentriMag VAD short-term/nonimplantable support out of clinical necessity for up to several months with satisfactory outcomes. Therefore, we expect that LVAD support with the current configuration can be continued for a relatively long time until the patient receives a heart transplant.

\section{References}

1. Cheng JM, den Uil CA, Hoeks SE, van der Ent M, Jewbali LS, van Domburg RT, et al. Percutaneous left ventricular assist devices vs. intra-aortic balloon pump counterpulsation for treatment of cardiogenic shock: a meta-analysis of controlled trials. Eur Heart J. 2009;30:2102-8.

2. Koerner MM, Jahanyar J. Assist devices for circulatory support in therapyrefractory acute heart failure. Curr Opin Cardiol. 2008;23:399-406.

3. Lietz K, Long JW, Kfoury AG, Slaughter MS, Silver MA, Milano CA, et al. Outcomes of left ventricular assist device implantation as destination therapy in the post-REMATCH era: implications for patient selection. Circulation. 2007;116: 497-505.

4. Rao V, Oz MC, Flannery MA, Catanese KA, Argenziano M, Naka Y. Revised screening scale to predict survival after insertion of a left ventricular assist device. J Thorac Cardiovasc Surg. 2003;125:855-62.

5. Pal JD, Klodell CT, John R, Pagani FD, Rogers JG, Farrar DJ, et al. Low operative mortality with implantation of a continuous-flow left ventricular assist device and impact of concurrent cardiac procedures. Circulation. 2009;120(suppl):S215-9.

6. Slaughter MS, Rogers JG, Milano CA, Russell SD, Conte JV, Feldman D, et al. Advanced heart failure treated with continuous-flow left ventricular assist device. N Engl J Med. 2009;361:2241-51. 